Prepared for the U.S. Department of Energy under Contract DE-AC05-76RL01830

\title{
Evaluation and Testing of the ADVANTG Code on SNM Detection
}

\author{
MW Shaver \\ AM Casella \\ RS Wittman \\ JW Hayes
}

September 2013

Pacific Northwest

NATIONAL LABORATORY

Proudly Operated by Battelle Since 1965 


\title{
DISCLAIMER
}

This report was prepared as an account of work sponsored by an agency of the United States Government. Neither the United States Government nor any agency thereof, nor Battelle Memorial Institute, nor any of their employees, makes any warranty, express or implied, or assumes any legal liability or responsibility for the accuracy, completeness, or usefulness of any information, apparatus, product, or process disclosed, or represents that its use would not infringe privately owned rights. Reference herein to any specific commercial product, process, or service by trade name, trademark, manufacturer, or otherwise does not necessarily constitute or imply its endorsement, recommendation, or favoring by the United States Government or any agency thereof, or Battelle Memorial Institute. The views and opinions of authors expressed herein do not necessarily state or reflect those of the United States Government or any agency thereof.

\author{
PACIFIC NORTHWEST NATIONAL LABORATORY \\ operated by \\ BATTELLE \\ for the \\ UNITED STATES DEPARTMENT OF ENERGY \\ under Contract DE-AC05-76RL01830
}

Printed in the United States of America
Available to DOE and DOE contractors from the Office of Scientific and Technical Information,
P.O. Box 62, Oak Ridge, TN 37831-0062;
ph: (865) 576-8401
fax: $(865)$ 576-5728
email: reports@adonis.osti.gov

\begin{abstract}
Available to the public from the National Technical Information Service, U.S. Department of Commerce, 5285 Port Royal Rd., Springfield, VA 22161 ph: (800) 553-6847 fax: $(703) 605-6900$ email: orders@ntis.fedworld.gov online ordering: http://www.ntis.gov/ordering.htm
\end{abstract}

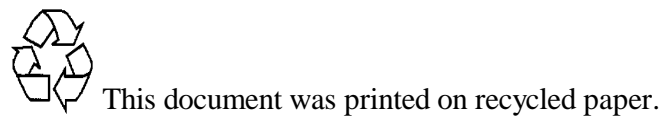




\section{Evaluation and Testing of the ADVANTG Code on SNM Detection}

MW Shaver

AM Casella

RS Wittman

JW Hayes

September 2013

Prepared for

the U.S. Department of Energy

under Contract DE-AC05-76RL01830

Pacific Northwest National Laboratory

Richland, Washington 99352 


\section{Summary}

Pacific Northwest National Laboratory (PNNL) has been tasked with evaluating the effectiveness of ORNL's new hybrid transport code, ADVANTG, on scenarios of interest to our NA-22 sponsor, specifically of detection of diversion of special nuclear material (SNM).

PNNL staff have determined that acquisition and installation of ADVANTG was relatively straightforward for a code in its phase of development, but probably not yet sufficient for mass distribution to the general user. PNNL staff also determined that with little effort, ADVANTG generated weight windows that typically worked for the problems and generated results consistent with MCNP. With slightly greater effort of choosing a finer mesh around detectors or sample reaction tally regions, the figure of merit (FOM) could be further improved in most cases. This does take some limited knowledge of deterministic transport methods. The FOM could also be increased by limiting the energy range for a tally to the energy region of greatest interest. It was then found that an MCNP run with the full energy range for the tally showed improved statistics in the region used for the ADVANTG run.

The specific case of interest chosen by the sponsor is the CIPN project from Las Alamos National Laboratory (LANL), which is an active interrogation, non-destructive assay (NDA) technique to quantify the fissile content in a spent fuel assembly and is also sensitive to cases of material diversion. Unfortunately, weight windows for the CIPN problem cannot currently be properly generated with ADVANTG due to inadequate accommodations for source definition. ADVANTG requires that a fixed neutron source be defined within the problem and cannot account for neutron multiplication. As such, it is rendered useless in active interrogation scenarios. It is also interesting to note that this is a difficult problem to solve and that the automated weight windows generator in MCNP actually slowed down the problem. Therefore, PNNL had determined that there is not an effective tool available for speeding up MCNP for problems such as the CIPN scenario.

With regard to the Benchmark scenarios, ADVANTG performed very well for most of the difficult, long-running, standard radiation detection scenarios. Specifically, run time speedups were observed for spatially large scenarios, or those having significant shielding or scattering geometries. ADVANTG performed on par with existing codes for moderate sized scenarios, or those with little to moderate shielding, or multiple paths to the detectors. ADVANTG ran slower than MCNP for very simply, spatially small cases with little to no shielding that run very quickly anyway. Lastly, ADVANTG could not solve problems that did not consist of fixed source to detector geometries. For example, it could not solve scenarios with multiple detectors or secondary particles, such as active interrogation, neutron induced gamma, or fission neutrons. 


\section{Table of Contents}

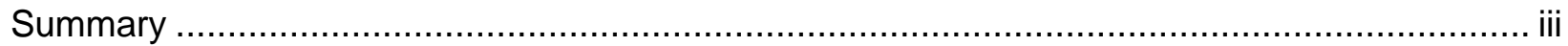

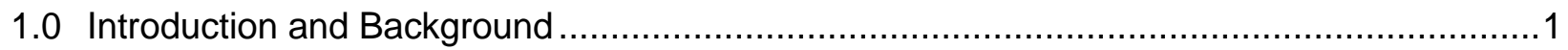

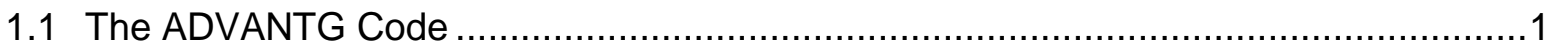

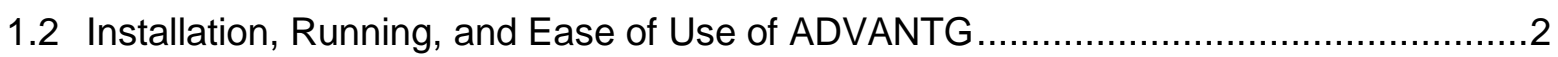

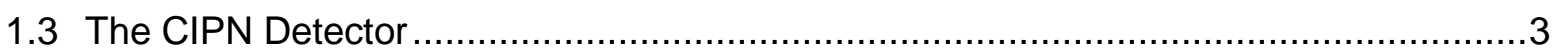

2.0 Evaluation of ADVANTG Performance on SNM Diversion Detection Scenarios.....................5

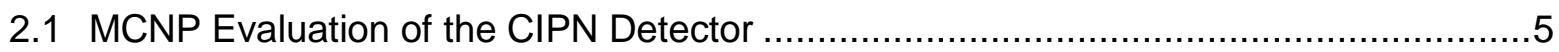

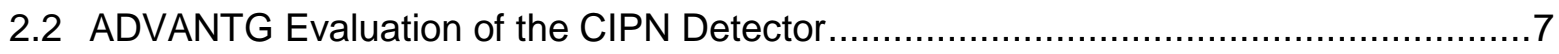

2.3 Summary of ADVANTG Performance on Benchmark Scenarios ............................... 8

2.3.1 Benchmarks ADVANTG Speeds Up ................................................. 8

2.3.2 Benchmark That ADVANTG Speeds up in Some Cases and Slows Down

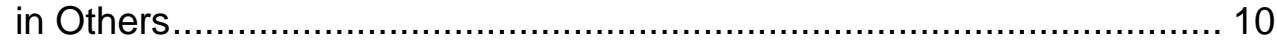

2.3.3 Benchmarks ADVANTG Can Solve, But Slowed Down ......................... 11

2.3.4 Benchmarks ADVANTG Cannot Solve ............................................... 12

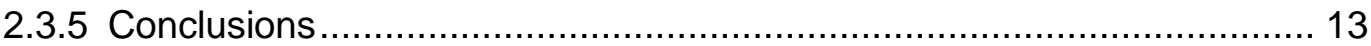

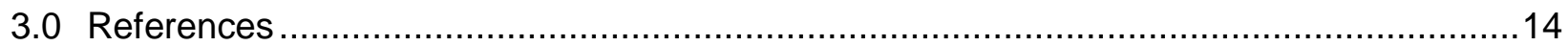

\section{List of Figures}

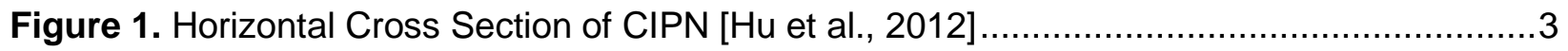

Figure 2. Vertical Cross Section of CIPN [Hu et al., 2012] ..............................................

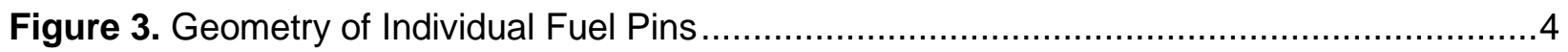

Figure 4. Spent Fuel Assembly Diagram with "zones" Colored for Identification [Hu et

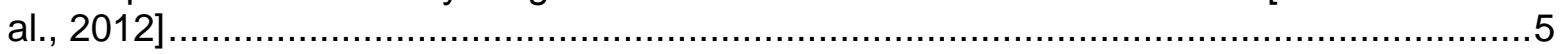

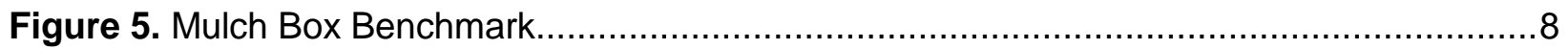

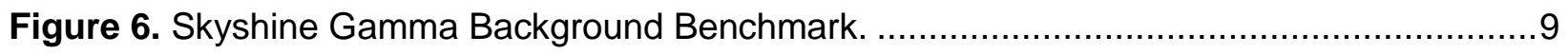

Figure 7. Spent Fuel Cask Gamma-Ray Scanner Benchmark [Caffrey 2009] ...........................

Figure 8. Generic Radiation Portal Monitor Benchmark .................................................

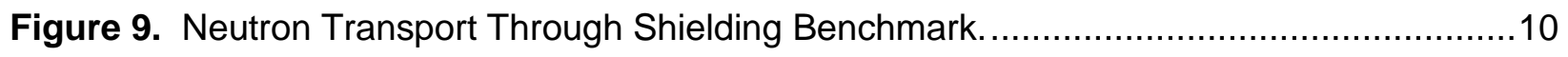

Figure 10. Polyethylene Coupled Neutron Gamma Benchmark..........................................11

Figure 11. 14.4.2 PANDA Benchmark [Stewart 1991] ......................................................11

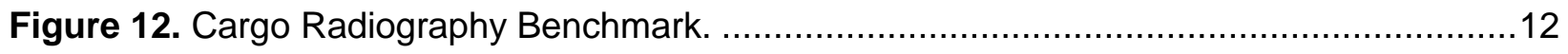

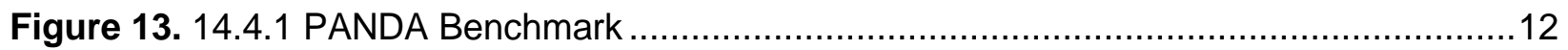

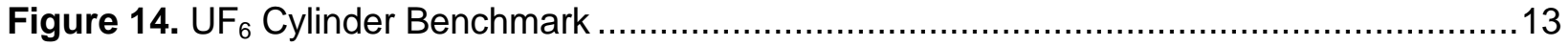




\subsection{Introduction and Background}

PNNL has been tasked with evaluating the effectiveness of ORNL's new hybrid transport code, ADVANTG, on scenarios of interest to our NA-22 sponsor, specifically of diversion of SNM. In addition, as a separate task on the same project PNNL had developed benchmarks

\subsection{The ADVANTG Code}

The Automate $\underline{\mathbf{d}}$ Variance Reduction Generator (ADVANTG) code is a Monte Carlo/ Deterministic Hybrid transport code developed by ORNL, using Denovo, and MCNP. Its approach for combining deterministic and Monte Carlo transport methods is the Consistent Adjoint Driven Importance Sampling (CADIS) method [Wagner et al. 1998]. The fundamental concept is to generate an approximate importance function from a fast-running deterministic adjoint calculation and use the importance map to construct variance reduction parameters that can accelerate tally convergence in the Monte Carlo simulation. The variance reduction parameters consist of space and energy-dependent weight window bounds and an importanceweighted (biased) source distribution. In the simulation, the weight windows are used to split or roulette particles that move toward relatively more or less important regions of phase space, respectively. The biased source ensures that particles are preferentially started where they are likely to contribute to the tally of interest. In addition, the source biasing parameters are consistent with the weight map; that is, source particles are sampled with weights that are at, or very near, the center of the window.

The CADIS method was developed to accelerate the estimation of an individual tally (e.g., a single cell tally with no energy bins). A newer hybrid method, the Forward-Weighted CADIS (FW-CADIS) method [Wagner et al. 2009], was developed to obtain relatively uniform statistical uncertainties across an arbitrary number of tallies (or tally bins). In the FW-CADIS method, a forward (as opposed to adjoint) deterministic calculation is initially performed and the results are used to construct an adjoint source that is weighted by the inverse of the forward flux in the regions of space and energy where the tallies are defined. Once the source has been computed, a deterministic adjoint calculation is performed and variance reduction parameters are computed using the CADIS methodology. The FW-CADIS method is flexible. It can be used to accelerate multiple, isolated tallies (e.g., cell or point-detector tallies) or it can be applied to large regions of space and/or energy.

The CADIS and FW-CADIS hybrid methods have been implemented in the ADVANTG code [Wagner et al. 2002, Mosher et al. 2009], which was developed to automate the process of generating variance reduction parameters for MCNP5. Given an MCNP input file and additional parameters for the deterministic calculation (e.g., spatial mesh, quadrature order, etc.), ADVANTG constructs an input for and drives the Denovo 3-D discrete ordinates package [Evans et al. 2010]. Denovo implements modern discretization schemes and solvers to generate solutions by the fastest and most robust methods available for structured grids. ADVANTG uses the output of Denovo to construct space and energy-dependent weight-window targets and a biased source, which are output as a WWINP file and SDEF cards, respectively. This output can be used directly with unmodified versions of MCNP5 and MCNPX. ADVANTG has been shown to produce highly-converged tally results in some challenging radiation detection problems [Mosher et al. 2009]. 


\subsection{Installation, Running, and Ease of Use of ADVANTG}

PNNL staff have determined that acquisition and installation of ADVANTG was relatively straightforward for a code in its phase of development, but probably not yet sufficient for mass distribution to the general user. Specifically, two main steps were performed to install ADVANTG on Linux. First Denovo and its prerequisite software and library packages where installed from their source distributions. Second ADVANTG and Lava were installed from their sources distributions, where Denovo, Lava and ADVANTG were included on the RSICC distribution CD. The two steps proceeded very closely along the notes given in the two files install-denovo.html and install.html, where early on it was decided that the default gcc (version 4.1.2) was not current enough to compile Denovo.

Therefore, all prerequisites (including gcc 4.6.1) were installed regardless of whether there were existing versions on the machine. The default /opt/src path was used for the build location - this was also the location for decompressing the Denovo, Lava and ADVANTG sources and the cross section libraries. As described in the notes, the command on the second line of the install scripts in advantg/doc/installation was a convenient way to download specific source distributions from the web. Also, the scripts themselves were helpful in setting-up environment variables and then, in some cases, running cmake to configure makefiles for installation. Only minor changes were made to install_cmake.sh and install_swig.sh, and the install_advantg.sh and install_lava.sh were made to resemble the examples in install.html. The code store.c and store.h seemed to be missing from the sprng package, but were readily found on the web.

Finally, after Lava and ADVANTG were installed and passed "make test" or "make check", both root and any user had to add paths to their logon script to ensure that PATH, LD_LIBRARY_PATH and PYTHONPATH, and then had to run Idconfig as root. The only thing not explicitly clear in the notes was setting PYTHONPATH, where it said to set it to the ADVANTG Python module location - there are several advantg Python module locations (e.g. directories off of: /opt/advantg/python). The path it wanted was:

The sample problems in /opt/advantg/examples were extremely clear and helpful in understanding how to set-up and run a problem. It was also clear how to modify the mesh and tally references in the examples to try ADVANTG for other MCNP models. With little effort on optimizing mesh and angular quadrature, PNNL staff determined that ADVANTG generated weight windows that typically worked for the problems and generated results consistent with MCNP. With slightly greater effort of choosing a finer mesh around detectors or sample reaction tally regions, the FOM could be further improved in most cases. This does take some limited knowledge of deterministic transport methods. The FOM could also be increased by limiting the energy range for a tally to the energy region of greatest interest. It was then found that an MCNP run with the full energy range for the tally showed improved statistics in the region used for the ADVANTG run. 


\subsection{The CIPN Detector}

The ${ }^{252} \underline{\mathbf{C}}$ Interrogation with Prompt $\underline{\text { Neutron }}$ (CIPN) detector is used in an active interrogation, non-destructive assay (NDA) technique to quantify the fissile content in a spent fuel assembly and is also sensitive to cases of material diversion. The detector use ${ }^{252} \mathrm{Cf}$ as an active neutron interrogator on one side of the fuel assembly and fission chambers on the other 3 sides. This is the scenario of interest this project's NA-22 sponsor has chosen to evaluate the effectiveness of the ADVANTG code. A top view of the scenario is shown below in Figure 1 and a side view is shown below in Figure 2. Each library has 39 distinct fuel pin material definitions Each of the fuel pins also has four radial sections as shown in Figure 3. Single pin: Cells $4-7$ are radial sections of fuel with different material properties. Cell 8 is clad, 11 is water.

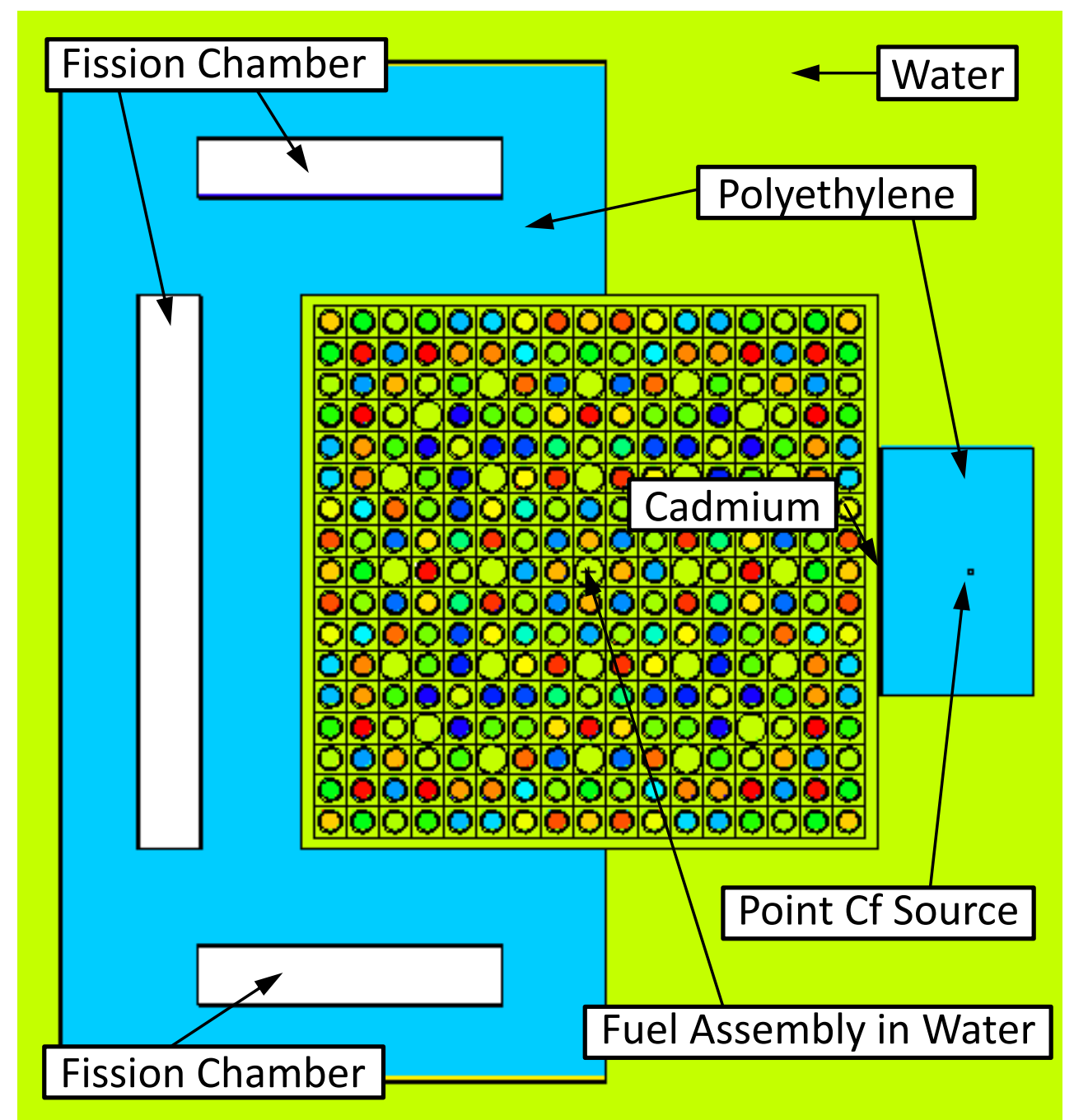

Figure 1. Horizontal Cross Section of CIPN [Hu et al., 2012] 


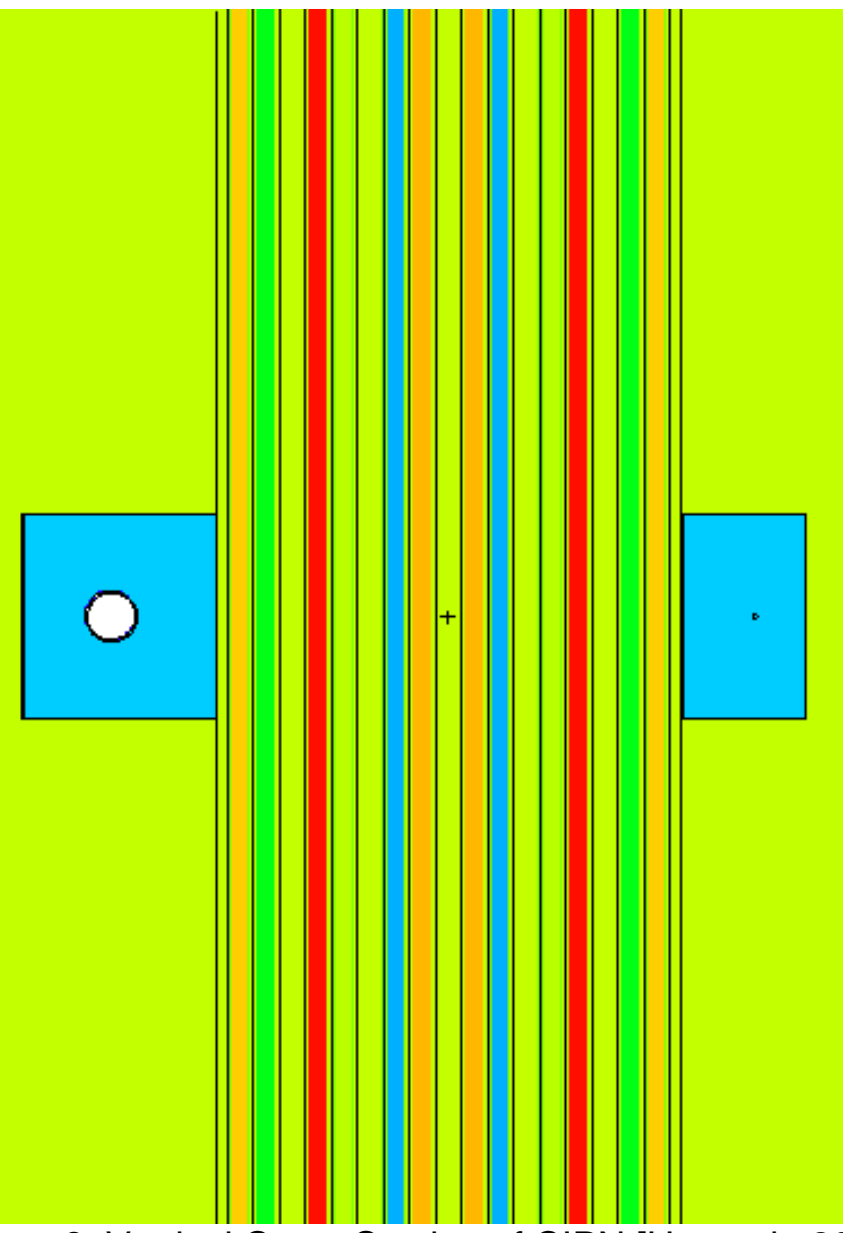

Figure 2. Vertical Cross Section of CIPN [Hu et al., 2012]

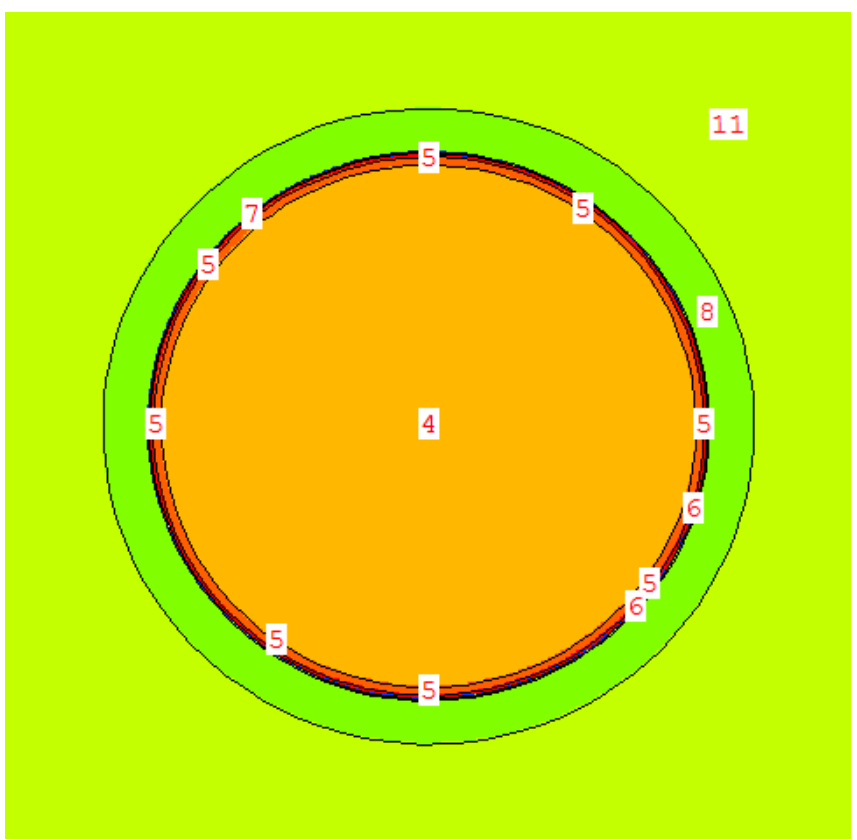

Figure 3. Geometry of Individual Fuel Pins 


\subsection{Evaluation of ADVANTG Performance on SNM Diversion Detection Scenarios}

\subsection{MCNP Evaluation of the CIPN Detector}

Figure 5 from $\mathrm{Hu}$, et al. shows the spent fuel assembly with colored regions representing "zones" where pin diversion scenarios were studied. It is shown below as Figure 4. The nine cases studied represent a different number of pins removed $(8,24$, or 40$)$ from each zone (inner, middle, and outer) and replaced with depleted uranium $(0.2 \%)$ rods. In each input file for a diversion case, a pin was replaced with the depleted uranium. Therefore, the thirty scenarios include three undiverted cases, one case for each burnup value of 15,30 , and $45 \mathrm{GWd} / \mathrm{tU}$, and nine cases of pin diversion for each burnup, for a total of 27 diversion scenarios. In terms of fuel definitions, the thirty benchmark cases are a variant on burnup only. There is no change in the geometry or other material definitions.

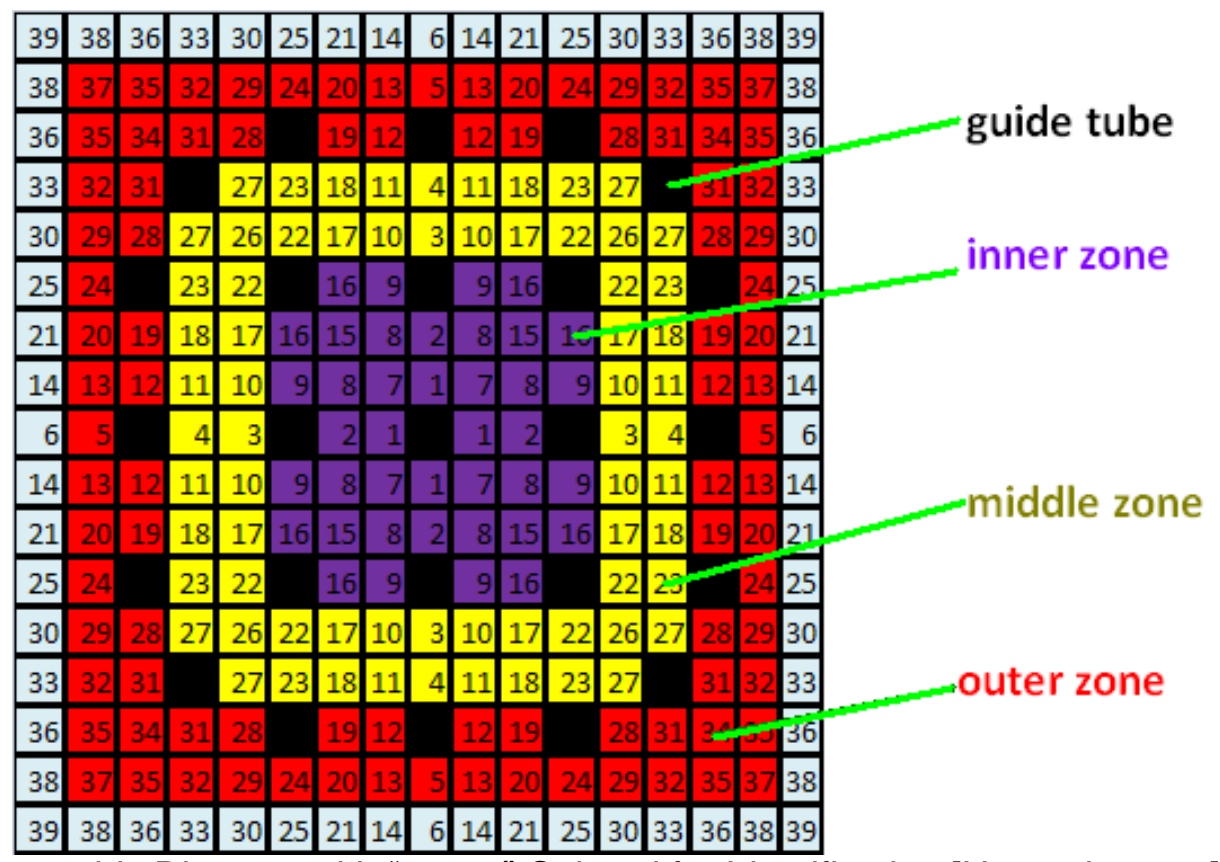

Figure 4. Spent Fuel Assembly Diagram with "zones" Colored for Identification [Hu et al., 2012]

The single most important metric in this scenario is the detector response given by the fission reaction rate tally in the union of all three fission chambers. Table 1 below (Hu et al) shows the change in detector response of each diversion scenario from the associated undiverted case. 
Table 1. LANL results using MCNPX [Hu et al., 2012]

\begin{tabular}{|c|c|c|c|c|c|c|}
\hline \multirow[b]{2}{*}{$\begin{array}{l}\text { Case } \\
\text { ID }\end{array}$} & \multirow[b]{2}{*}{$\begin{array}{l}\text { location of } \\
\text { diverted rods }\end{array}$} & \multirow[b]{2}{*}{$\begin{array}{c}\text { \# rods } \\
\text { diverted }\end{array}$} & \multirow[b]{2}{*}{$\begin{array}{c}\% \text { mass } \\
\text { diverted }\end{array}$} & \multicolumn{3}{|c|}{$\begin{array}{l}\text { Count rate change from the } \\
\text { corresponding full case }\end{array}$} \\
\hline & & & & $\begin{array}{c}15 \mathrm{GWd} / \mathrm{tU} \\
(\%)\end{array}$ & $\begin{array}{c}30 \mathrm{GWd} / \mathrm{tU} \\
(\%)\end{array}$ & $\begin{array}{c}45 \mathrm{GWd} / \mathrm{tu} \\
(\%)\end{array}$ \\
\hline 1 & & 8 & & $-4.6+/-0.30$ & $-3.2+/-0.27$ & $-2.4+/-0.32$ \\
\hline 2 & inner zone & 24 & & $-15.4+/-0.28$ & $-10.1+/-0.29$ & $-8.0+/-0.32$ \\
\hline 3 & & 40 & & $-27.5+/-0.28$ & $-19.4+/-0.28$ & $-14.1+/-0.31$ \\
\hline 4 & & 8 & & $-3.8+/-0.30$ & $-2.8+/-0.31$ & $-2.0+/-0.32$ \\
\hline 5 & middle zone & 24 & & $-11.6+/-0.29$ & $-7.8+/-0.30$ & $-6.1+/-0.32$ \\
\hline 6 & & 40 & & $-20.0+/-0.28$ & $-14.1+/-0.26$ & $-11.0+/-0.31$ \\
\hline 7 & & 8 & & $-4.1+/-0.30$ & $-2.7+/-0.31$ & $-2.4+/-0.33$ \\
\hline 8 & outer zone & 24 & & $-9.8+/-0.29$ & $-7.2+/-0.30$ & $-5.9+/-0.32$ \\
\hline 9 & & 40 & & $-17.3+/-0.28$ & $-12.8+/-0.26$ & $-10.4+/-0.32$ \\
\hline
\end{tabular}

Only the three undiverted cases were sent to PNNL from LANL, so PNNL reconstructed the 27 diversion scenarios and reran them to reproduce the results. First, the thirty cases were run without any weight windows or other variance reduction techniques in MCNP to get a base analog run time. The PNNL results to reproduce the LANL results are shown below in Table 2 and are consistent with the LANL results. These runs were intended to be used as a baseline to evaluate how much MCNP's weight windows generator sped up the runs versus how much ADVANTG did. These cases took 2.3 days computer run time each, which totals about 2.3 months of computer run time. The cases were run on a 128 processor cluster, so they only took 21 hours of actual wall-clock time.

Table 3. PNNL results using MCNP5 analog (i.e. no weight windows)

\begin{tabular}{|ccccccc|}
\hline & & & & \multicolumn{3}{c|}{$\begin{array}{c}\text { Count rate change from the } \\
\text { corresponding full case }\end{array}$} \\
\cline { 5 - 7 } Case & location of & \# rods & $\%$ mass & $15 \mathrm{GWd} / \mathrm{tU}$ & $30 \mathrm{GWd} / \mathrm{tU}$ & $45 \mathrm{GWd} / \mathrm{tU}$ \\
$\mathrm{ID}$ & diverted rods & diverted & diverted & $(\%)$ & $(\%)$ & $(\%)$ \\
\hline 1 & & 8 & $-4.4+/-0.34$ & $-2.9+/-0.33$ & $2.0+/-0.32$ \\
2 & inner zone & 24 & $-14.5+/-0.34$ & $-10.2+/-0.33$ & $-6.9+/-0.32$ \\
3 & & 40 & $-27.4+/-0.34$ & $-19.6+/-0.34$ & $-13.7+/-0.32$ \\
\hline 4 & & 8 & $-3.5+/-0.34$ & $-2.8+/-0.33$ & $-1.7+/-0.32$ \\
5 & middle zone & 24 & $-11.7+/-0.34$ & $-8.5+/-0.33$ & $-6.1+/-0.32$ \\
6 & & 40 & $-19.7+/-0.34$ & $-13.6+/-0.34$ & $-10.6+/-0.32$ \\
7 & & 8 & $-4.1+/-0.35$ & $-3.2+/-0.33$ & $-2.4+/-0.32$ \\
8 & outer zone & 24 & $-10.5+/-0.35$ & $-8.1+/-0.34$ & $-6.1+/-0.32$ \\
9 & & 40 & $-16.9+/-0.34$ & $-13.2+/-0.34$ & $10.0+/-0.32$ \\
\hline
\end{tabular}

Next, each of the 30 cases was run using MCNP's automatically generated weight windows for variance reduction on the same cluster of computers as the previous run. The results for these 
cases are shown below in Table 3 and are consistent with the previous runs. These runs took just over three days of computer run time each, totaling three months of total computer run time. This meant that the cases with the weight windows for variance reduction actually ran about 20 processor days slower, meaning the weight windows in MCNP actually slowed down the run time by about $30 \%$.

Table 2. PNNL results using MCNP5 w/ weight windows

\begin{tabular}{|c|c|c|c|c|c|}
\hline \multirow[b]{2}{*}{$\begin{array}{c}\text { Case } \\
\text { ID }\end{array}$} & \multirow[b]{2}{*}{$\begin{array}{l}\text { location of } \\
\text { diverted rods }\end{array}$} & $\begin{array}{l}\text { \# rods } \\
\text { diverted }\end{array}$ & \multicolumn{3}{|c|}{$\begin{array}{l}\text { Count rate change from the } \\
\text { corresponding full case }\end{array}$} \\
\hline & & $\begin{array}{l}\% \text { mass } \\
\text { diverted }\end{array}$ & $\begin{array}{c}15 \mathrm{GWd} / \mathrm{tU} \\
(\%)\end{array}$ & $\begin{array}{c}30 \mathrm{GWd} / \mathrm{tU} \\
(\%)\end{array}$ & $\begin{array}{c}45 \mathrm{GWd} / \mathrm{tU} \\
(\%)\end{array}$ \\
\hline 1 & & 8 & $-4.4+/-0.31$ & $-2.5+/-0.29$ & $-2.4+/-0.27$ \\
\hline 2 & inner zone & 24 & $-14.9+/-0.31$ & $-9.6+/-0.30$ & $-7.3+/-0.27$ \\
\hline 3 & & 40 & $-27.6+/-0.32$ & $-19.3+/-0.30$ & $-14.2+/-0.28$ \\
\hline 4 & & 8 & $-4.1+/-0.31$ & $-2.4+/-0.29$ & $-2.2+/-0.27$ \\
\hline 5 & middle zone & 24 & $-11.7+/-0.31$ & $-7.8+/-0.30$ & $-6.3+/-0.27$ \\
\hline 6 & & 40 & $-20.4+/-0.32$ & $-14.1+/-0.30$ & $-11.2+/-0.27$ \\
\hline 7 & & 8 & $-4.2+/-0.31$ & $-2.6+/-0.29$ & $-2.5+/-0.27$ \\
\hline 8 & outer zone & 24 & $-10.7+/-0.31$ & $-7.8+/-0.30$ & $-6.2+/-0.27$ \\
\hline 9 & & 40 & $-17.5+/-0.31$ & $-12.7+/-0.30$ & $-10.6+/-0.27$ \\
\hline
\end{tabular}

The slowdown in the runs by using MCNP's variance reduction of atomically generated weight windows was due to the fact that this scenario is one of active interrogation.

\subsection{ADVANTG Evaluation of the CIPN Detector}

Weight windows for the CIPN problem cannot currently be properly generated with ADVANTG due to inadequate accommodations for source definition. ADVANTG requires that a fixed neutron source be defined within the problem and cannot account for neutron multiplication. As such, it is rendered useless in active interrogation scenarios. ADVANTG will generate a weight window set for the MCNP input deck utilized for comparison of analog MCNP results to results of calculations using an MCNP generated weight window set. However, these weight windows will not account for any fission neutrons born within the used fuel rods being irradiated by the Cf-252 source.

After discussing the issue with ORNL a way to solve the problem was identified. In order to obtain ADVANTG-generated weight windows for the CIPN problem, an arduous two-step approach must be applied in which much care must be exercised in order to properly avoid large error propagation. First, an MCNP case must be run that utilizes carefully crafted tallies that track the production of fission neutrons in each of the used fuel pins in the target assembly. Any uncertainty in the determination of the induced fission neutron sources within the used fuel assembly will propagate to the second step of the calculation, so it is important to obtain results with low relative errors. 
Once the induced fission source is determined, it needs to be coupled properly with the Cf-252 source itself in order to produce a complete neutron source for the ADVANTG weight window generation. This means that the original MCNP file used to calculate the induced neutron source within the used fuel pins must be modified to include the induced neutron source and the tallies must be modified to account for reaction rates within the neutron detectors instead of the induced neutrons in the used fuel pins. This modified MCNP input file can then be used to generate the ADVNATG weight window set, which must be used with a third MCNP input file. This third MCNP input file will have the same source definition as the first MCNP input file (neutrons only coming from the Cf-252 source), but with the tallies matching the second input file (reaction rate within the neutron detectors). One must pay very close attention to each step and all associated modifications to ensure that the factors influencing the final results of the process are properly identified.

Ultimately, it was determined that to run MCNP twice (once to get the induced neutron flux and once to get the detector response) would actually be slower than running MCNP analog without weight windows to get the detector response and was therefore, not done.

\subsection{Summary of ADVANTG Performance on Benchmark Scenarios}

The other task of this project was to develop a computational radiation detection benchmark set using ADVANTG as the representative hybrid transport code. For the nine benchmark cases that were completed, there were four where significant speed increases were observed; two that gave speedups in some conditions, but not others; one and a half that it could solve, but it actually slowed the calculations down; and one and a half that ADVANTG could not solve. A summary of the ADVANTG run times of these cases is given below. For more detailed report on the benchmark results see Shaver, et al. 2013.

\subsubsection{Benchmarks ADVANTG Speeds Up}

For the mulch box benchmark, shown in Figure 5, ADVANTG sped up the MCNP calculation by $96 \%$, showing a large improvement of run time.

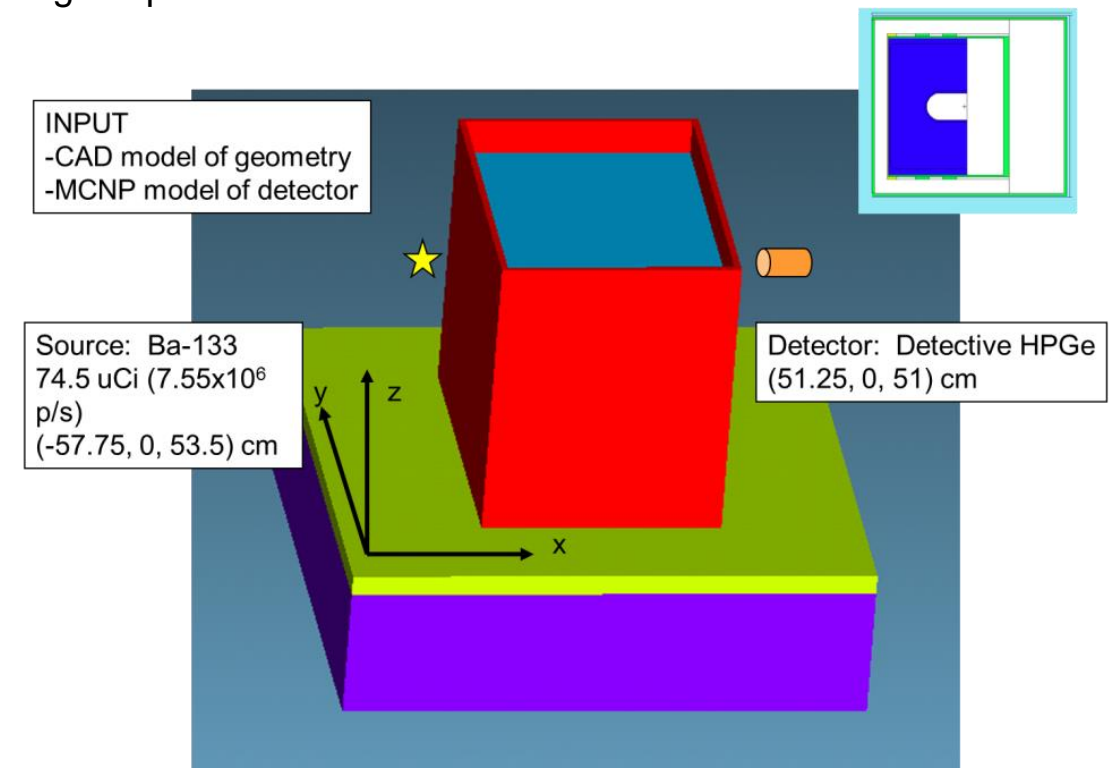

Figure 5. Mulch Box Benchmark. 
For the skyshine benchmark, shown in Figure 6, ADVANTG ran two orders of magnitude faster than MCNP, showing a large improvement in run time.

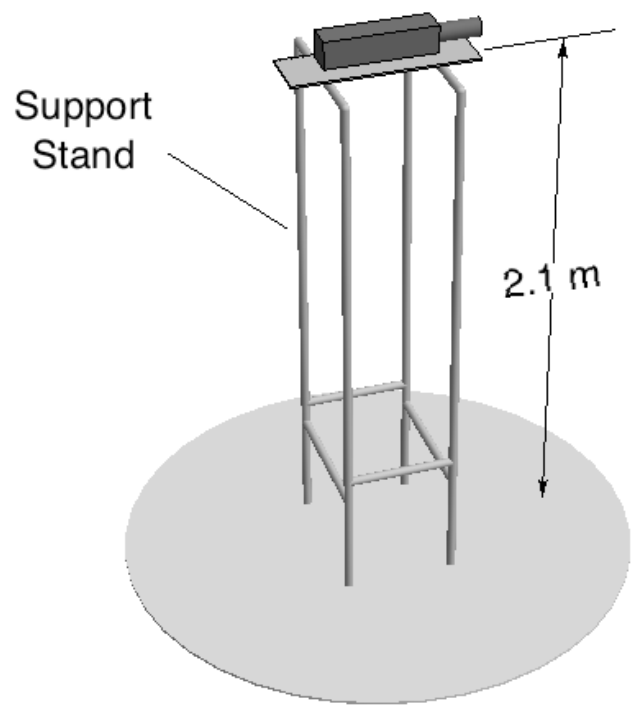

Figure 6. Skyshine Gamma Background Benchmark.

For the spent fuel cask scanner benchmark, shown below in Figure 7, ADVANTG ran an order of magnitude faster than MCNP, showing a large improvement in run time.

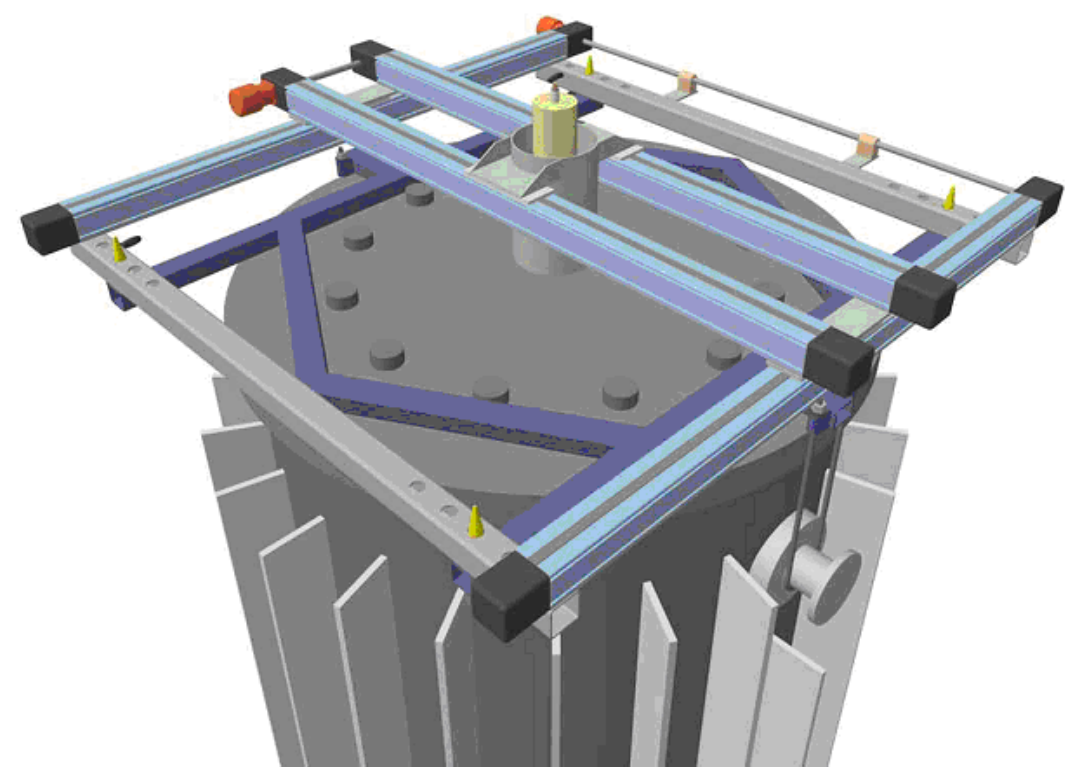

Figure 7. Spent Fuel Cask Gamma-Ray Scanner Benchmark [Caffrey 2009]. 
For the spent generic radiation portal monitor benchmark, shown below in Figure 8, ADVANTG ran an order of magnitude faster than MCNP, showing a large improvement in run time.

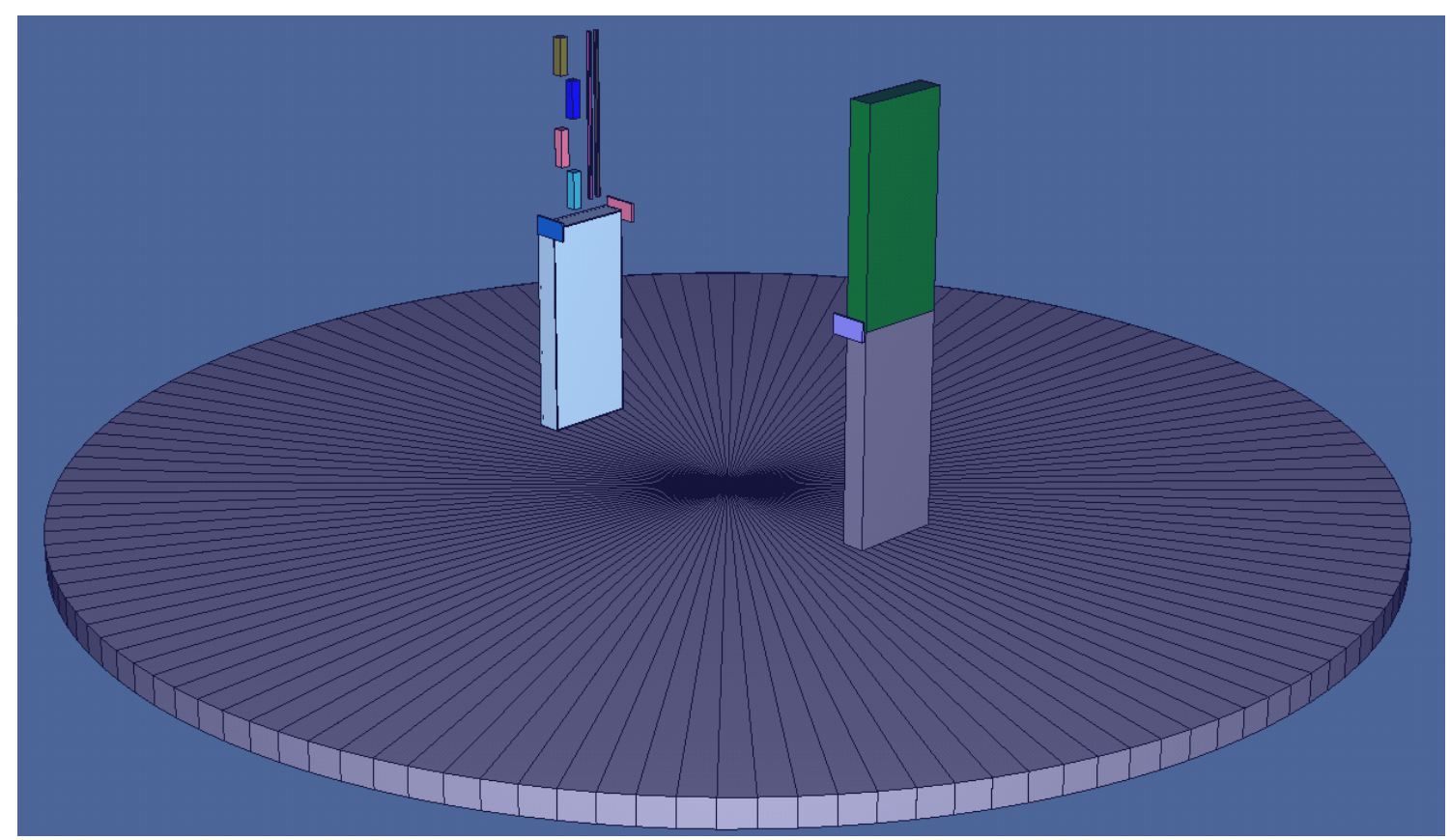

Figure 8. Generic Radiation Portal Monitor Benchmark.

\subsubsection{Benchmark That ADVANTG Speeds up in Some Cases and Slows Down in Others}

For the Neutron Transport Benchmark shown in Figure 9, ADVANTG gave a slower speed with no shield or with only the right most, thinnest shield. This is because the overhead of generating the weight windows was slower than running an MCNP case with little to no attenuation. However, ADVANTG did yield speed increases with the thicker shields.

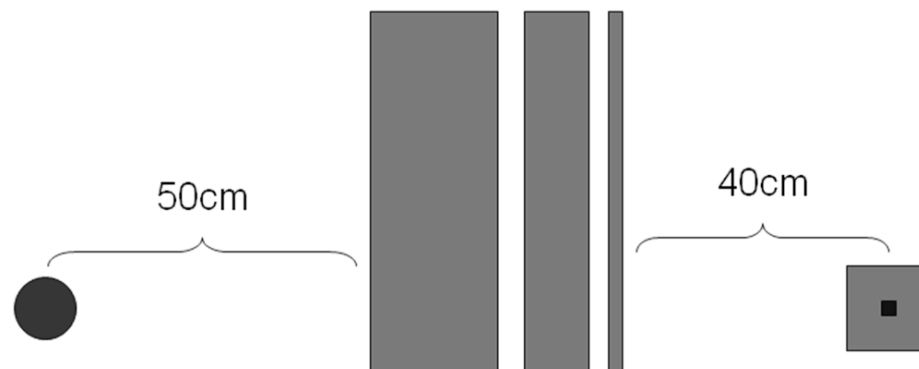

$5 \mathrm{~cm}$ radius poly or air sphere point source in center
$8 \times 8 \times 11 \mathrm{~cm}$ poly block $1 \times 1 \times 5 \mathrm{~cm} \mathrm{He}^{3}$ tube at $4 \mathrm{~atm}$

$20 \mathrm{~cm}, 10 \mathrm{~cm}$ and $1 \mathrm{~cm}$

Figure 9. Neutron Transport Through Shielding Benchmark. 
The ADVANTG results for the polyethylene coupled neutron, gamma benchmark, shown in Figure 10, were essentially identical to the MCNP results and all of the peaks converged faster except for the $4.439 \mathrm{MeV}$ peak, which made the whole run slower. Also, the overall spectrum ran slower. Part of the issue was that many histories were born outside of the weight windows. Another part of the issue is that ADVANTG can't optimize the weight windows generation for an $\mathrm{n}$,gamma problem. For this problem the weight windows are optimized for the neutron source, however the gammas that it generates happen to be generally coming from and going to the same directions, so it works. However, ADVANTG would not always work well for other coupled particle problems, specifically if the source and detector were off axis. If one or two peaks were the only metrics of interest, ADVANTG could potentially yield a speedup in the problem, which would be substantial.

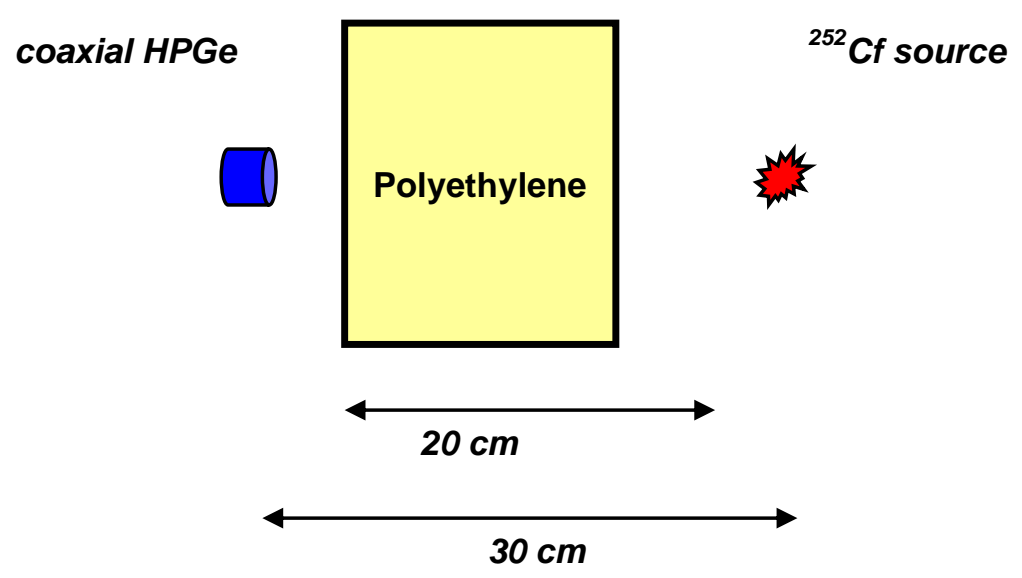

Figure 10. Polyethylene Coupled Neutron Gamma Benchmark.

\subsubsection{Benchmarks ADVANTG Can Solve, But Slowed Down}

The ADVANTG runs yielded essentially identical results to MCNP for the 14.4.2 PANDA benchmark shown in Figure 11, but were, on average, a factor of twelve slower than MCNP.

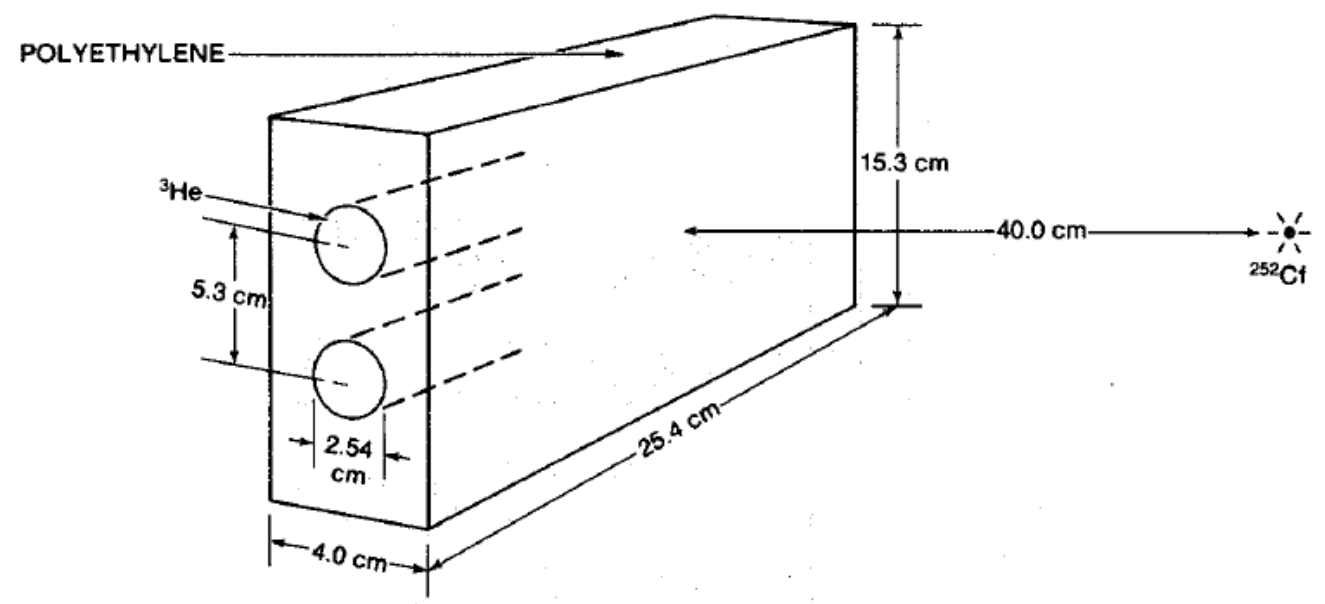

Figure 11. 14.4.2 PANDA Benchmark [Stewart 1991]. 
For the radiography benchmark, below in Figure 12, ADVANTG accurate results, but ran about $63 \%$ slower than MCNP alone. The issues with the hybrid methodology is that point tallies, which are used for radiography cases, essentially have infinite variance (poor performance when collisions are near the detector) and are themselves a form of variance reduction and one that is more suited to the problem than weight windows. Specifically, the geometry itself is also mostly air with a long mean free path and few thick obstacles.

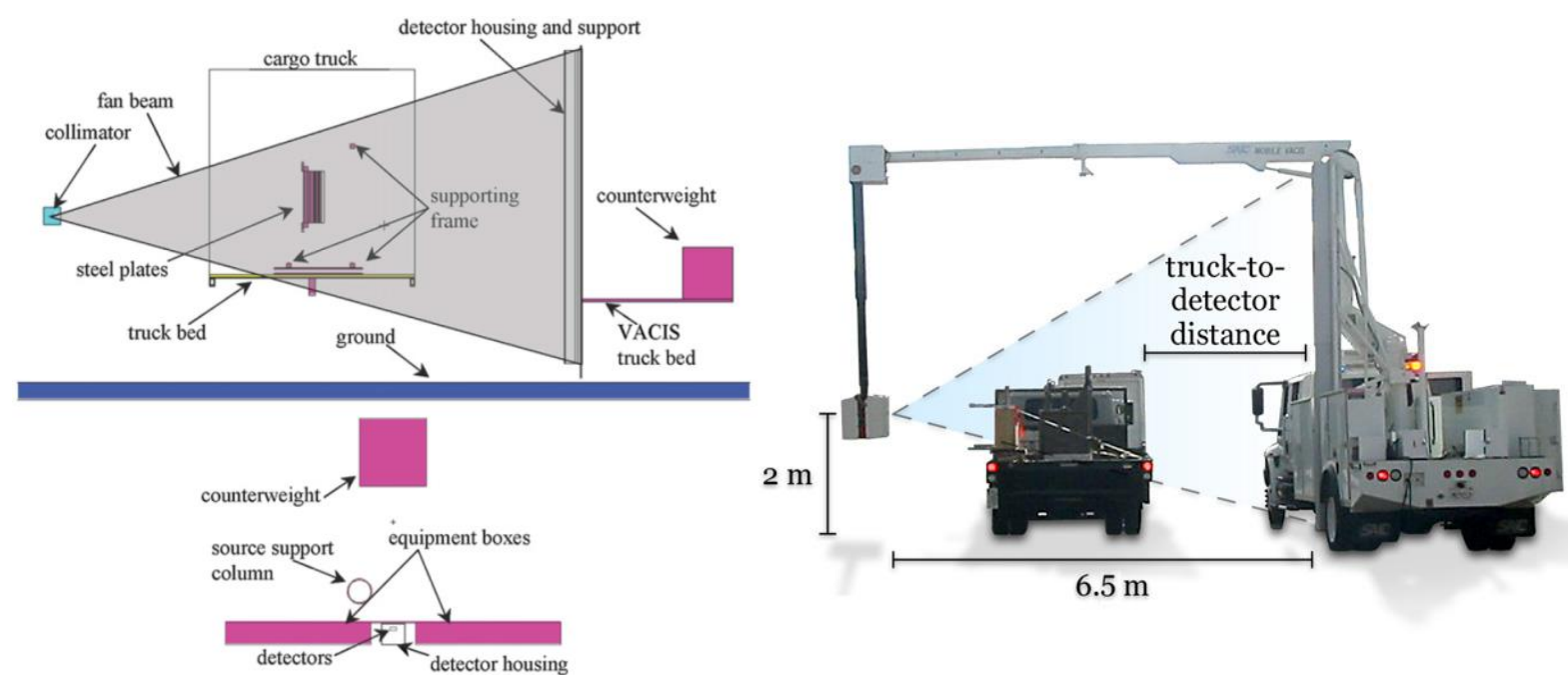

Figure 12. Cargo Radiography Benchmark.

\subsubsection{Benchmarks ADVANTG Cannot Solve}

ADVANTG could not solve the 14.4.1 PANDA benchmark shown in Figure 13, because there were too many points of interest (detectors) to force the neutrons into. Weight windows are usually optimized to go from one fixed source to one detector.

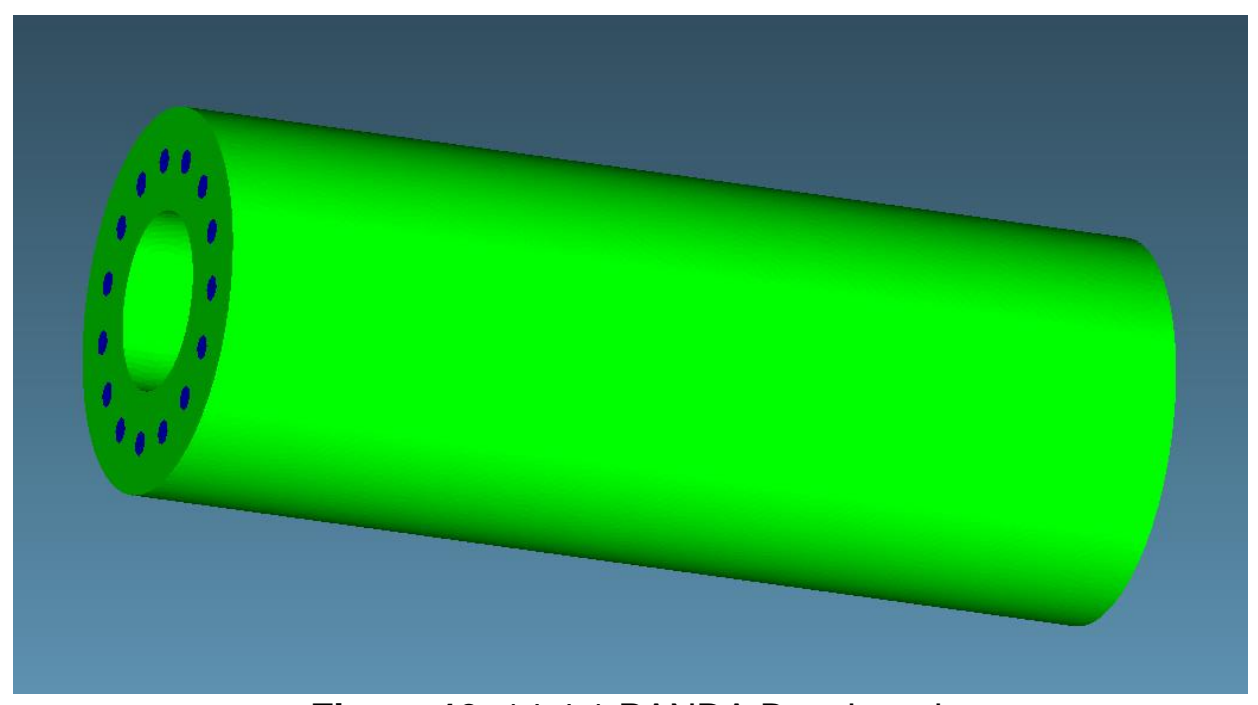

Figure 13. 14.4.1 PANDA Benchmark 
ADVANTG could also not solve the UF $_{6}$ cylinder benchmark, shown in Figure 14, because fission is not considered in fixed-source Denovo calculations and MCNP5 does not support an F8 tally with and coupled neutron gamma problem while using weight windows. Also, weight windows cannot be optimized for the $\mathrm{n}$, gamma sources.
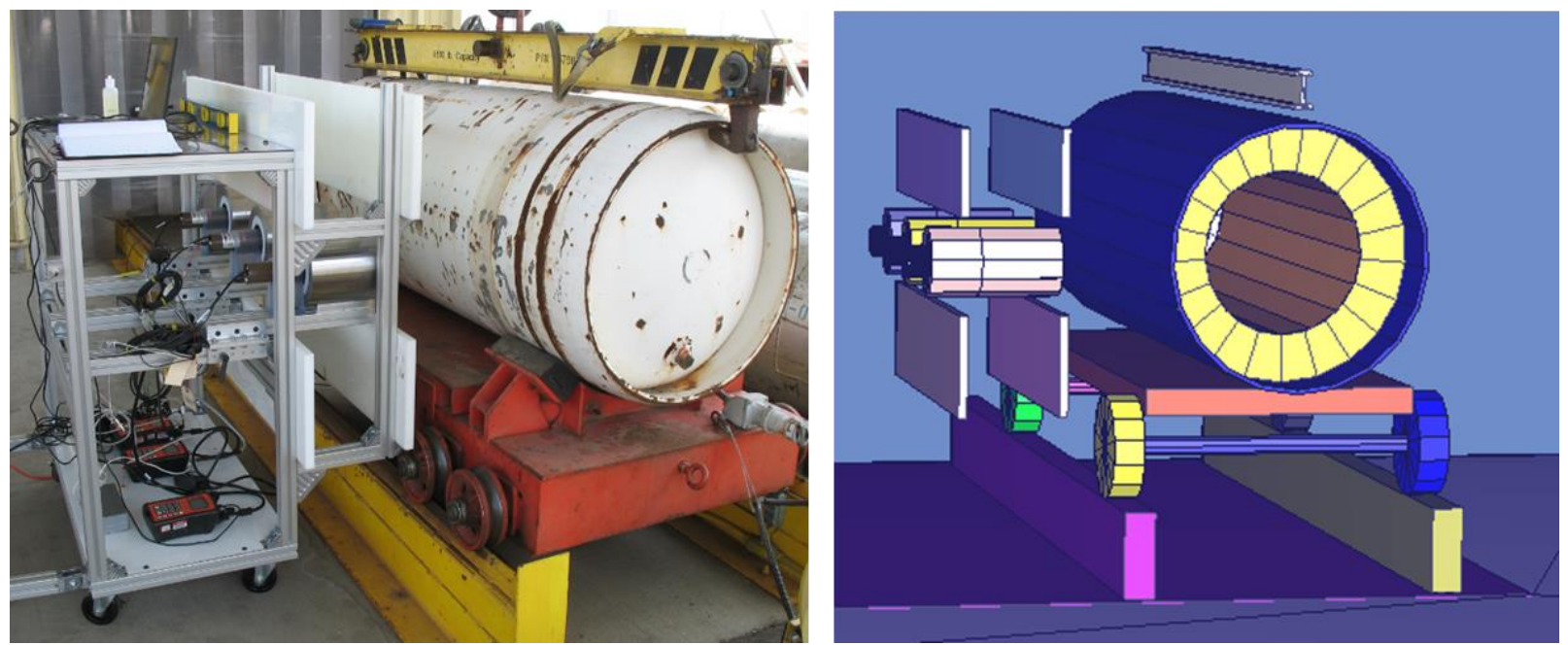

Figure 14. $U_{6}$ Cylinder Benchmark

\subsubsection{Conclusions}

ADVANTG performed very well for most of the difficult, long-running, standard radiation detection scenarios. Specifically, run time speedups were observed for spatially large scenarios, or those having significant shielding or scattering geometries. ADVANTG performed on par with existing codes for moderate sized scenarios, or those with little to moderate shielding, or multiple paths to the detectors. ADVANTG ran slower than MCNP for very simply, spatially small cases with little to no shielding that run very quickly anyway. Lastly, ADVANTG could not solve problems that did not consist of fixed source to detector geometries. For example, it could not solve scenarios with multiple detectors or secondary particles, such as active interrogation, neutron induced gamma, or fission neutrons. 


\subsection{References}

Caffrey A.J., "Recent Test Results for the INL Spent-Fuel Cask Gamma-Ray Scanner," Presented at the IAEA US SP Annual Meeting Presented on May 19, 2009.

Evans T.M., A.S. Stafford, K.T. Clarno, "Denovo - A New Three-Dimensional Parallel Discrete Ordinates Code in SCALE"Nuclear Technology, June 2010.

Hu, Jianwei, S.J. Tobin, H.O. Menlove, D. Henzlova, J. Gerhart, M.T. Swinhoe, S. Croft, "Developing the Californium Interrogation Prompt Neutron Technique to Measure Fissile Content and to Detect Diversion in Spent Nuclear Fuel Assemblies", Journal of Nuclear Materials Management, XL, 40 (3), pp. 49-58, 2012.

Lewis E. E. and W. F. Miller, "Computational Methods of Neutron Transport", John Wiley and Sons, New York, 1984.

Mosher S.W., T.M. Evans, T.M. Miller, and J.C. Wagner, "Efficient Transport Simulations of Difficult Detection Problems Using ADVANTG," 2009 IEEE Nuclear Science Symposium and Medical Imaging Conference, Orlando, Florida, October, 2009.

Parringron, J. R. et al. "Nuclides and Isotopes Fifteenth Edition: Chart of the Nuclides". San Jose, CA: Lockheed Martin and General Electric Nuclear Energy, 1996.

Shaver, M.W., A.M. Casella, R.S. Wittman, and B.S. McDonald, "Radiation Detection Computational Benchmark Scenarios", PNNL-22794, Pacific Northwest National Laboratory, Richland, WA, 2013.

Stewart J.E., "Ch. 14: Principles of Total Neutron Counting, in Passive Nondestructive Assay of Nuclear Materials" Los Alamos National Laboratory, LA-UR-90-732, NUREG/CR-5550, 1991.

Wagner J. C. and A. Haghighat, "Automatic Variance Reduction of Monte Carlo Shielding Calculations Using the Discrete Ordinates Adjoint Function," Nucl. Sci. Eng., 128, 186-208, 1998.

Wagner J. C., "An Automated Deterministic Variance Reduction Generator for Monte Carlo Shielding Applications, "Proceedings of the American Nuclear Society 12th Biennial RPSD Topical Meeting, Santa Fe, New Mexico, 2002.

Wagner J. C., E. D. Blakeman, and D. E. Peplow, "Forward-Weighted CADIS Method for Variance Reduction of Monte Carlo Calculations of Distributions and Multiple Localized Quantities," Intl. Conf. Math. Comp. Meth. Reactor Phys. (M\&C 2009), Saratoga Springs, New York, 2009.

Waters, L.S., Editor, “MCNPX User's Manual”, Version 2.3.0, LA-UR-02-2607, Los Alamos National Laboratory, April 2002.

X-5 Monte Carlo Team, "MCNP - A General Purpose Monte Carlo N-Particle Transport Code, Version 5", LA-UR-03-1987, Los Alamos National Laboratory, April 2003. 



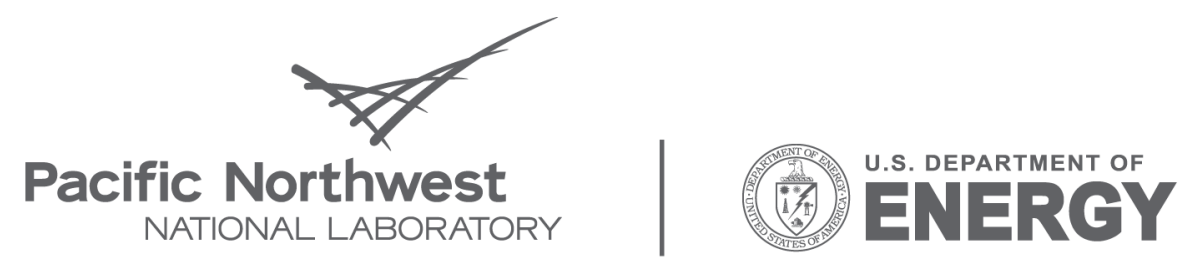

Proudly Operated by Battelle Since 1965

902 Battelle Boulevard

P.O. Box 999

Richland, WA 99352

1-888-375-PNNL (7665)

www.pnl.gov 